\title{
ASPECTOS DA ORALIDADE NA PRODUÇÃO TEXTUAL DE ALUNOS DO 5० ANO DO ENSINO FUNDAMENTAL
}

\author{
ASPECTS OF ORALITY IN THE TEXTUAL PRODUCTION OF STUDENTS \\ OF THE 5th YEAR OF FUNDAMENTAL EDUCATION
}

\section{Rosemeire Pereira de Matos Garcia ${ }^{1}$ Romário Duarte Sanches ${ }^{2}$}

\begin{abstract}
RESUMO: Este trabalho trata da influência da oralidade na produção textual dos alunos do $5^{\circ}$ ano do ensino fundamental da Escola Municipal de Ensino Fundamental Associação dos Moradores do Bairro do Barro Branco, localizada em Santo Antônio do Tauá - PA. O objetivo principal foi mostrar como a língua oral, falada no cotidiano, influencia a escrita dos alunos no momento da produção de textos escritos quando não estão sendo monitorados. Assim, este estudo assume os pressupostos da sociolinguística educacional (BORTONI-RICARDO, 2004; 2005), com propostas voltadas para o ensino de língua materna na educação. Como metodologia, propusemos aos alunos do $5^{\circ}$ ano a produção de textos com tema da atualidade e a partir disso buscamos analisar a influência da fala na escrita textual. Os resultados obtidos registram marcas recorrentes da fala que se aproximam da transcrição grafemática, evidenciando que os discentes ainda não conseguem separar a língua falada nas rodas de conversa informal da linguagem exigida pela norma padrão. Isso se evidencia por meio de alguns trechos de textos produzidos pelos alunos, como: "Om dia en vinia da casa da minia tia"... " "en qiría um futuro milio"... " "eu ligo a TV eu vejo no jornal gente morendo purisso essa e a minha escolha". Neste sentido, fica clara a necessidade de intervenções do professor, com práticas que tratem essas diferenças e conscientizem o discente acerca da existência de espaços sociais para o uso de formas linguísticas específicas.
\end{abstract}

Palavras-chave: Oralidade; Escrita; Produção textual; Ensino de línguas.

ABSTRACT: This work deals with the influence of orality in the textual production of students of the 5th year of elementary school of the Escola Municipal de Ensino Fundamental Associação dos Moradores do Bairro do Barro Branco, located in Santo Antonio do Tauá - PA. The main objective was to show how oral language, spoken in everyday life, influences students' writing when writing texts are not being monitored. Thus, this study assumes the assumptions of educational sociolinguistics (BORTONI-RICARDO, 2004; 2005), with proposals aimed at teaching mother tongue in education. As a methodology, we proposed to 5 th year students the production of texts with current themes and from this we seek to analyze the influence of speech in textual writing. The results obtained record recurrent speech marks that approximate the graphical transcription, evidencing that the students still cannot separate the spoken language in the wheels of informal conversation from the language required by the standard norm. This is evidenced by some excerpts from texts produced by students, such as "Om dia eu vinia da casa da minia tia"... / "en qiría um futuro milio"... " "eu ligo a TV eu vejo no jornal gente morendo purisso essa e a minha escolha". In this sense, it is clear the need for teacher interventions, with practices that address these differences and make the student aware of the existence of social spaces for the use of specific linguistic forms.

Keywords: Orality; Writing; Text production; Language teaching.

\footnotetext{
${ }^{1}$ Especialista em Estudos Linguísticos e Análise Literária (UEPA). Contato: matos.taua@hotmail.com.

${ }^{2}$ Doutor em Letras (Linguística) pela Universidade Federal do Pará (UFPA) e Professor da Universidade do Estado do Amapá (UEAP). Contato: romariodsanches@gmail.com.
} 


\section{INTRODUÇÃO}

A escola ainda prioriza o ensino da escrita na sua forma padrão, e a coloca em posição de destaque na construção dos saberes, deixando em segundo plano a forma oralizada de representação da língua. Bortoni-Ricardo (2005) afirma que a escola pode exercer uma grande influência na aquisição de variantes da língua, mesmo privilegiando um ensino de língua padrão.

Nessa perspectiva, faz-se necessário investigar como as práticas sociais de letramento podem influenciar no contexto de sala de aula, ou seja, em que sentido os textos orais produzidos pelos alunos no seu cotidiano podem interferir e/ou influenciar nas produções escritas propostas nas atividades escolares.

Neste contexto, o trabalho discute como as práticas desenvolvidas na sala de aula podem influenciar na aquisição da escrita, compreendendo que o falar e o escrever são ações em que o sujeito se relaciona consigo, com o meio em que vive e nas suas relações, como mostra Bortoni Ricardo (2004, p. 23) "esses são os três ambientes onde uma criança começa a desenvolver o seu processo de sociabilização: a família, os amigos e a escola".

Desenvolver uma investigação a respeito dos modos de falar e os modos de escrever nos possibilita compreender como os saberes da oralidade integram-se aos saberes da produção escrita. Ao observar as práticas da sala de aula, no que se refere às atividades em torno da oralidade, podemos constatar a falta de prática do uso do texto oral como objeto de exploração no trabalho escolar. Ou ainda, como aponta Antunes (2003, p. 24) "uma equivocada visão da fala, como o lugar privilegiado para a violação das regras da gramática”.

O objetivo principal aqui é investigar a influência das marcas da oralidade nas produções textuais dos alunos do $5^{\circ}$ ano do ensino fundamental da escola Associação dos Moradores do Bairro do Barro Branco, localizada na cidade de Santo Antônio do Tauá - PA.

O trabalho está dividido em quatro seções. A primeira aborda a relação da escola e o ensino de língua portuguesa. A segunda mostra um esboço da fala para a escrita. A terceira apresenta os procedimentos metodológicos como: o tipo de pesquisa, os sujeitos selecionados, o local da pesquisa e os instrumentos utilizados. A quarta discorre sobre os resultados da pesquisa, perpassando pelo perfil dos entrevistados, análise dos textos produzidos por eles e a influência da oralidade no texto escrito.

\section{O ENSINO DE LÍNGUA PORTUGUESA NA ESCOLA}

Para discutir o ensino de língua portuguesa na escola é preciso compreender como esse processo se dá de fato na sala de aula. O que se percebe tanto no passado quanto na atualidade é um ensino de língua portuguesa voltada para o estudo da gramática tradicional e geralmente ignorando as variedades da língua e suas manifestações orais produzidos em sala de aula pelos alunos.

A oralidade é compreendida como um espaço onde o falante transgride com frequência a língua padrão. Segundo Bortoni-Ricardo (2005), o ensino de língua materna deve partir, além da língua padrão, dos diferentes dialetos, pois tanto a língua padrão quanto o dialeto rural, por exemplo, fazem parte do repertório linguístico dos falantes. Neste sentido, ambos devem ser usados na sala de aula, cumprindo funções diferenciadas.

A escola precisa saber usar a língua portuguesa, no que tange à produção textual, de uma forma mais contextualizada, compreendendo que a gramática é necessária, mas não é suficiente para construção dos múltiplos saberes sobre a língua. O ensino da língua portuguesa escrita tem seu lugar privilegiado na escola, subsidiada por meio da gramática tradicional.

Sabemos que uma língua natural não é constituída de forma aleatória, ela é composta por regras que a constitui, tanto no campo da semântica quanto na sintaxe, cumprindo a sua função que é estabelecer comunicação em qualquer contexto social. Neste sentido, Antunes (2014, p. 39) 
diz que "existe sempre um contexto, uma situação social qualquer, onde o que dizemos pode assumir um determinado sentido e cumprir uma determinada função comunicativa".

Vivemos em uma realidade em que o professor questiona o uso de tantas teorias e que as mesmas não condizem com as múltiplas realidades vivenciadas no cotidiano da sala de aula, contudo, é preciso compreender que todas as práticas ora vividas, certamente foram embasadas em algum estudo anteriormente realizado em prol do ensino de língua portuguesa, assim como de tantas outras áreas do conhecimento.

A escola pode exercer uma grande influência na aquisição de variantes da língua, mesmo privilegiando um ensino de língua padrão. Como afirma Bortoni Ricardo (2005):

(...) a influência da escola na língua não deve ser procurada no dialeto vernáculo dos falantes, mas sim em estilos formais, monitorados. Por isso, assumir, também, a linguagem usada na sala de aula como objeto de pesquisa da Sociolinguística Educacional. (BORTONI-RICARDO, 2005, p.182).

Nessa perspectiva, é necessário investigar como as práticas de letramento podem influenciar no contexto da sala de aula, ou seja, em que sentido os textos orais produzidos pelos alunos no seu cotidiano podem interferir ou influenciar nas produções escritas propostas nas atividades escolares.

Não se pode generalizar, mas para a escola o ensino da língua portuguesa está diretamente relacionado ao ensino de gramática normativa, logo está vinculado às repetições e absorção das regras nela contidas.

De acordo com a visão de muita gente, para o êxito do trabalho pedagógico com a linguagem, basta ensinar gramática; não raro entendida como nomenclaturas, ou como um simples conjunto de regras, mesmo aquelas anacrônicas, inconscientes e descabidas. (ANTUNES, 2014, p. 28).

Vale ressaltar que para os alunos, essa forma de trabalhar a língua portuguesa torna-se desinteressante e faz dela um vilão de grande parte dos discentes no seu período escolar. Esse contato muitas vezes é traumático e na pior das hipóteses incide em evasão escolar, como afirma Antunes (2014):

Dessa forma, o trabalho com a linguagem passa a não ter interesse, a ser uma coisa sem sentido social, da qual nos livraremos logo que podermos. Ou, por outro ângulo, faz parte das políticas de silenciamento, que provocam nos alunos um sentimento de depreciação em relação a seu próprio falar, sentimento que emudece até mesmo os mais confiantes. (ANTUNES, 2014, p. 28).

A escola precisa conceber no ensino da Língua Portuguesa métodos que tratem do sentido, do para quê e o porquê estudar essa área do conhecimento; e mostrar que esse conhecimento vai além das normas e regras pré-estabelecidas pela gramática tradicional. Um conhecimento que seja pautado na praticidade dos elementos que constitui esse estudo, que mostre outras faces e pontos de vistas que redirecionem esse ensino para práticas que vão além do ler e escrever bem. Que concretize seus objetivos, porém, se revele ao aluno como fonte mediadora entre a pluralidade linguística existentes em nossa sociedade e os currículos que tratam da organização e aplicabilidade dessa disciplina.

\section{DA FALA PARA ESCRITA}

A fala surge da necessidade que o homem tem de manter contato com o outro. Sabemos que as civilizações primitivas evoluíram, e o que antes era feito por meio de gestos e sons e rascunhos grafados em paredes, agora passa a ser representado pela fala e pela escrita. Vale ressaltar que uma 
não anula a outra, ainda que se tenha dado a escrita um legado de grande importância social, a fala tem suas intenções comunicativas para atender as expectativas dos seus falantes.

(...) Isso implica entender que uma modalidade não tem primazia sobre a outra, a despeito do elevado valor social que tradicionalmente foi legado à escrita, mas sim, constroem o mundo, dando-lhe significado, cada uma com os recursos que compõem a sua lexicogramática (...) (MARCUSCHI, 2004, p. 20).

Ao ingressar na escola, a criança já possui competência como usuária de sua língua materna, sua habilidade em operar sua língua é notória e atende suas necessidades de estabelecer comunicação com seu grupo de fala. Por meio de um contínuo, a língua falada vai se desenvolvendo até o momento em que a sala de aula apresenta a língua escrita, o que para a criança será inicialmente algo inusitado e complexo, iniciando, assim, o processo de escolarização. Neste sentido Marcuschi (2007) comenta que:

(...) Além disso, a criança, o jovem ou o adulto já sabe falar com propriedade e eficiência comunicativa sua língua materna quando entra na escola, e sua fala influencia a escrita, sobretudo no período inicial da alfabetização, já que a fala tem modos próprios de organizar, desenvolver e manter as atividades discursivas. (MARCUSCHI, 2007, p. 15)

A língua é um dos maiores patrimônios de um povo. Nela identificamos a história dos povos e sua trajetória. Seguramente, todos concordamos que a língua é um dos bens mais preciosos e mais valorizados por todos os seres humanos em qualquer época, povo e cultura.

A oralidade possui fatores que a influenciam, assim como: a regionalidade, a cultura, o local de moradia, se zona urbana ou rural, dentre outros. Da mesma forma a escrita possui seus elementos constitutivos. Tanto o texto oral quanto o escrito possuem padrões que os descrevem de acordo com o grau de complexidade de cada um, como aponta Marcuschi (2004):

Os estudiosos apontam que textos orais e textos escritos apresentam padrões de variação em diferentes dimensões as quais devem ser consideradas para sua descrição. Indicam, assim, que tais dimensões envolvem diferenças de estrutura e organização, diferenças na frequência de traços linguísticos, diferenças nos usos (...). (MARCUSCHI, 2004.p.23).

Para Marcuschi (2007) as relações entre oralidade e escrita se dão num contínuo ou gradação perpassada pelos gêneros textuais, e não na observação dicotômica de características polares. Para o autor, a melhor forma de observar a relação fala-escrita é contemplá-la num contínuo de textos orais e escritos, seja na atividade de leitura, seja na produção escrita. Percebe-se assim que existem textos que são propriedades da fala e outros que são da escrita, do nível formal ao informal, mais monitorado e menos monitorado.

Neste sentido, tanto Bortoni-Ricardo (2004) quanto Marcuschi (2007) compreendem que a escola deve trabalhar esses dois níveis: a fala e a escrita. E não priorizar somente a escrita.

Percebe-se que as duas modalidades apresentam variação, contudo, é no texto oral e na sua transcrição que, preconceituosamente, se ouve falar em "erros de português". Para Bortoni-Ricardo (2004) os "erros de português" são simplesmente diferenças entre as variedades da língua. Não havendo razão para considerar uma língua superior ou inferior a outra. Para a autora, o ensino de língua materna deve partir, além da língua padrão, dos diferentes dialetos, pois tanto a língua padrão como o dialeto rural, por exemplo, fazem parte do repertório linguístico dos falantes.

Podemos citar como exemplo dessa transição, a maneira como um indivíduo vindo do meio rural e aluno do curso de letras, no meio de sua parentela, exerce seu papel social de filho de pessoas sem estudos e no seu local de estudo, não vai poder exercer o mesmo papel social, tendo que assumir o papel de aluno do curso de letras. A linguagem usada para esses dois ambientes é totalmente diferente, assim como a forma de monitorar a fala e a escrita. Dessa forma, o indivíduo que 
sabe utilizar bem a sua língua é aquele que consegue transitar entre os dois contextos e seus eixos de monitoração:

Figura 01: Contínuo de oralidade

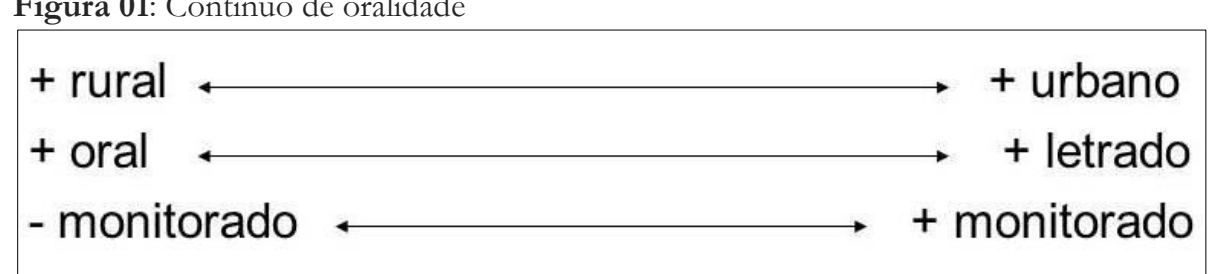

Fonte: Extraído de Bortoni-Ricardo (2004, p. 64).

Esses eixos acima (cf. figura 01) são apresentados por Bortoni Ricardo (2004) para representar a transição de contextos de fala e de escrita mais rural, mais urbano, mais oral, mais letrado, menos monitorado e mais monitorado. Para a autora os eventos de letramento que se estabelecem à margem direita do contínuo de oralidade representam os de norma culta, e os eventos que se estabelecem à margem esquerda do contínuo estão no repertório não formal. Neste sentido, o indivíduo que sai da zona rural e se insere na cultura urbana precisará saber usar a linguagem mais monitorada em situações formais e a menos monitorada em situações menos formais.

Diante de tantos dilemas encontrados na sociedade, no que tange às variedades linguísticas, a escola tem papel fundamental para com as classes populares que utilizam uma linguagem menos escolarizada e de menor prestígio social, cabendo a ela ensinar novas práticas de letramento escolar, na tentativa de oportunizar aos alunos o conhecimento de variedades da língua de maior prestígio social. Neste sentido Bortoni-Ricardo (2005) mostra que:

A escola não pode ignorar as diferenças sociolinguísticas. Os professores e, por meio deles, os alunos têm de estar bem conscientes de que existem duas ou mais formas de dizer a mesma coisa. E mais, que essas formas alternativas servem a propósitos comunicativos distintos e são recebidas de maneira diferenciada pela sociedade. (BORTONI-RICARDO, 2005, p.15).

Durante o trabalho com a escrita poderá haver ocorrência do modo como o aluno operacionaliza a fala, principalmente no processo de alfabetização da criança. Para Bortoni-Ricardo (2005) a eficiência das técnicas de alfabetização e do treinamento da escrita vai depender dos antecedentes sociolinguísticos do aluno.

Com os avanços dos estudos sociolinguísticos, a oralidade tem conquistado seu espaço na sociedade, embora as práticas em sala de aula sejam muito voltadas para a valorização do texto escrito e/ou formal, por haver uma preocupação com as recorrentes correções gramaticais. De uma maneira tímida se vislumbra o uso de atividades que prestigiam o texto oral na sala de aula ainda que inconscientemente, em trabalhos de exposição. É importante ressaltar que o trabalho com o texto oral assume papel importante na formação dos alunos por se tratar de uma prática que contribui para o enriquecimento do repertório dos falantes. Observamos, por exemplo, a força da oralidade por meio da prática de gêneros tais como: entrevistas, debates, palestras, comunicações em congressos, entre outros.

É indispensável mencionar que algumas modalidades de apresentação dos textos orais obedecem a regras oriundas do texto escrito dentro das normas chamadas cultas. Os discentes precisam compreender essa flexibilidade que é possível trabalhar no uso da língua e tê-la como um aliado nos modos monitorados de apresentação da mesma. Segundo Bortoni-Ricardo (2005):

Do ponto de vista da sociolinguística educacional, para operar de uma maneira aceitável, um membro de uma comunidade de fala tem de aprender o que dizer e como dizê-lo apropriadamente, a qualquer interlocutor e em quaisquer circunstâncias. (BORTONI-RICARDO, 2005, p.61). 
Apesar de haver relação entre fala e escrita, percebemos que a escrita é muito diferente do ato de falar, principalmente porque a escrita não se adquire imediatamente, ela é processual e depende de fatores gramaticais. Nesse sentido, Marcuschi (2004) diz que a língua escrita é um componente que se ensina, requerendo um conjunto de estratégias próprias para sua transmissão e aquisição.

Cabe salientar que a escola precisa desenvolver a escrita para atender às necessidades da sociedade para com seu contexto político, socioeconômico, cultural e ainda formar cidadãos letrados aptos a compreender sua comunicação gráfica, por ser este um meio exigido em sociedades grafocêntricas.

\section{PROCEDIMENTOS METODOLÓGICOS}

A pesquisa aqui proposta é de abordagem qualitativa, pois envolve um processo de reflexão e análise da realidade através da utilização de técnicas para a compreensão detalhada de como se dá a influência dos saberes da oralidade mobilizada na prática da produção textual.

O espaço escolhido para a realização da pesquisa foi a Escola Associação dos Moradores do Bairro do Branco, fundada em 13 de maio de 1993, situada à Travessa Santa Rita de Cássia no 888, no Bairro do Barro Branco, na cidade de Santo Antônio do Tauá. A escola foi construída em parceria com o Governo do Estado do Pará. O Estado se responsabilizou pelas contratações dos professores e demais servidores, enquanto que a Associação em contrapartida cedeu o terreno para construção do Prédio com a contribuição da mão de obra da comunidade. Posteriormente, por ocasião do processo de municipalização, o governo municipal assumiu o funcionamento da mesma. A primeira gestora foi à professora Maria Benedita Furtado Sousa, que naquele momento exercia o cargo de Presidente da Associação.

A escola surgiu a partir da grande vontade que a professora Maria Benedita, (conhecida na cidade como Dona Bena) tinha de construir uma Escola-Creche para que pudesse acolher o grande número de crianças, filhos de pequenos agricultores, que viviam na comunidade sem nenhum tipo de atividade educacional. E também por possuir terras ali na localidade, conhecida como Barro Branco, tendo este nome devido a grande quantidade de barro branco presentes nas margens dos igarapés que circundam aquele espaço.

Atualmente, a Escola é mantida através de parceria com a Prefeitura Municipal e está em processo de organização de seus documentos para regularização e autorização de funcionamento. A Escola é da rede pública municipal e de pequeno porte. Ressalta-se que a mesma sedia entidades como os Alcoólicos Anônimos e suas reuniões são as quartas-feiras à noite. A escola conta com 275 alunos matriculados, dos quais 66 são alunos do $5^{\circ}$ ano e formam três turmas, 01 no turno da manhã e 02 no turno da tarde. A maioria deles são filhos de famílias humildes, porém, existe um percentual de alunos filhos de professores e pequenos comerciantes do bairro e bairros vizinhos.

\subsection{Características físicas da escola}

Esta unidade escolar ocupa uma área medindo 1.605,28 $\mathrm{m}^{2}$, e seu espaço físico é composto das seguintes dependências: 08 salas de aula, 01 área livre, 01 refeitório, 01 sala de professores, 01 cozinha com depósito de alimentos, 01 secretaria, 01 sala de direção, 01 sala de leitura, 01 sala de orientação pedagógica, 01 sala de informática (desativada) que atualmente funciona como sala de vídeo, 01 quadra de areia, 01 banheiro para funcionários, 01 banheiro para a educação infantil, 01 banheiro masculino para ensino fundamental, 01 banheiro feminino para ensino fundamental, 01 salão de recepções. Diante da descrição feita acima, percebemos que a escola carece de uma melhor infraestrutura e de investimento público nos espaços de ensino-aprendizagem, como a construção de uma biblioteca, sala de vídeo, sala de leitura e a ativação da sala de informática. 


\subsection{Níveis de modalidades de ensino}

A escola oferta as seguintes modalidades de ensino, Educação Infantil que atende crianças na faixa etária de 04 anos no Pré I; 05 anos no Pré II, ambas no Turno Matutino; no Ensino Fundamental atende crianças na faixa etária de 06 anos a 14 anos, de $1^{\circ}$ ano a $5^{\circ}$ ano. Sendo que de $1^{\circ}$ ao $5^{\circ}$ anos no turno Matutino, e de $3^{\circ}$ ao $5^{\circ}$ anos no turno Vespertino.

\subsection{Perfis dos alunos}

A escola atende um público com faixa etária entre 04 e 14 anos, e estão inseridos nas turmas de educação infantil e ensino fundamental menor. Situa-se num bairro periférico e parte de seu alunado vive em situação de risco, com casos de crianças oriundas de lares desestruturados, por separação dos pais em razão de alcoolismo e dependência química, situação essa que contribui bastante para a evasão escolar e retenção dos alunos nos estudos.

A pesquisa foi realizada em uma turma do $5^{\circ}$ ano do ensino fundamental da escola Associação dos Moradores do Bairro do Barro Branco. A turma tem 24 alunos entre 10 e 11 anos de idade e funciona no turno da manhã, foi escolhida para fazer parte da pesquisa por se tratar de uma turma assídua, já que as turmas do turno da tarde tem baixa frequência. A escolha dessa turma deu-se pelo fato de investigarmos as influências socioculturais de ambientes distintos nas atividades de oralidade e escrita, além de outros fatores como o geográfico e o econômico, já que a turma é bastante mista e é constituída por alunos de realidades socioculturais e econômicas diferentes.

A atividade de produção textual foi aplicada a 24 alunos da turma supracitada, porém, somente dez (10) deles foram selecionados por considerar que apenas estes conseguem escrever, já que os demais estão em processo de alfabetização.

\subsection{Intervenções em sala de aula}

As atividades de intervenção em sala de aula foram distribuídas em cinco momentos:

$1^{\circ}$ Momento: Antecedendo a elaboração dos textos escritos foram apresentados aos alunos alguns documentários ${ }^{3}$ que discutem o tema "Violência Mundial".

$2^{\circ}$ Momento: $\mathrm{Na}$ sequência foi realizada a partir das apresentações dos documentários, uma discussão com os discentes sobre esse contexto em nível global e do espaço local (o município de Santo Antônio do Tauá), já que a violência e o número de mortes têm sido alarmantes nos últimos meses no município. Abrimos a oportunidade para que os alunos dessem suas contribuições sobre o assunto, esse momento do trabalho não foi tão simples quanto esperávamos, uma vez que para alguns dos discentes existe uma barreira a ser rompida no que tange à apresentação oral.

$3^{\circ}$ Momento: A partir da discussão em sala e dos documentários assistidos, os alunos produziram textos sobre a temática "violência". Para isso, disponibilizamos uma folha em branco contendo a temática da redação.

$4^{\circ}$ Momento: Tendo sido recolhida as redações, realizamos a seleção das produções que foram utilizadas para a coleta dos dados da pesquisa.

$5^{\circ}$ Momento: Os alunos realizaram a refacção textual. Foram devolvidos a eles os textos corrigidos, apontando seus desvios na escrita, em que a marca da fala do cotidiano estavam presentes em seus registros escritos, essa metodologia causou impacto nos discentes, uma vez que essa é uma prática pouco comum de revisão de textos. Como atividade complementar à proposta foi sugerido que cada aluno reescrevesse o texto com o mesmo tema, e agora percebendo uma organização diante dos desvios apontados na correção. Selecionamos para a análise os textos dos alunos que

\footnotetext{
${ }^{3}$ Exibimos os seguintes documentários: Guerras entre nações; Violência doméstica; Feminicídio; Homicídios no município vitimando adolescentes.
} 
conseguiram escrever, haja vista, que alguns ainda estão em processo de alfabetização e não conseguem produzir textos escritos. Os textos foram analisados com base na reescrita dos mesmos e foram catalogados os desvios ainda existentes na produção, uma vez que na refacção textual percebemos outros desvios que foram encontrados. Assim, apresentamos aos alunos que existem várias formas de dizer a mesma coisa, porém, no caso da modalidade escrita formal é necessário obedecer a certos critérios, por se tratar de um gênero que precisa utilizar normas tidas como padrão.

\section{ANÁliSE dOS TEXTOS PRODUZIDOS PELOS ALUNOS}

Nesta seção apresentamos a análise das marcas da oralidade encontradas nas produções dos textos produzidos pelos alunos. Nesses textos verificamos que todos os discentes apresentam problemas em suas produções, seja de caráter gramatical, de acentuação, de desvios ortográficos, seja na forma como transcrevem as palavras. Mesmo diante de tais constatações, iremos nos ater somente as marcas da língua falada e sua influência na língua escrita na produção textual. Com isso constatamos os seguintes fenômenos: a) troca de vogais por outras e/ou por consoantes; b) supressão das consoantes " $r$ " e "s"; c) omissão dos dígrafos; d) uso do til ( ) em palavras com nasalidade; e) acréscimo de vogais; f) palavras grafadas como um único vocábulo formal.

a) Troca de vogais por outras e/ou por consoantes

Nesses casos observamos que o uso das vogais nas palavras obedece à pronúncia utilizada pelo aluno na fala. Cagliari afirma que a criança "[...] escreve um u em vez de o, pois fala [u] e não [o] [...]" (1993, p.139). Esse fenômeno foi possível de ser observado nos textos em que houve a troca da vogal "o" pela vogal "u" nos seguintes trechos:

Texto 01: "... se tornou um caus".

Texto 01: "no jornal tem gente morendo purisso".

b) Supressão das consoantes "r" e "s"

Percebemos que alguns alunos, na oralidade, não marcam o infinitivo de alguns verbos ou o plural de palavras. Nos textos escritos, observamos que a consoante " $r$ " é suprimida.

Texto 02: “... pode mata muita jete...".

Texto 02: "... mulhe jovem criança...".

Texto 02: “... e vai fica sozinho...”.

No caso da consoante "s", os alunos não usam a marcação do plural, o que é muito comum na fala de pessoas de classes sociais diferentes, instruídas ou não. É uma das marcas mais fortes da oralidade. Isso ocorreu nos textos 04 e 05 :

Texto 04: “... no meio de todo os problema...".

Texto 05: “... e tanbén as criança...”.

c) Omissão dos dígrafos

Por ser o dígrafo fenômeno fonético (que ao ser pronunciado emite um único fonema ou som), ao transcrever, o discente omite o dígrafo e escreve da forma como ouve a palavra, como mostra os trechos dos textos 01, 03 e 08 :

Texto: 01: “... tem gente morendo de fome asasinado...”.

Texto: 03: “... guerra nos países... Alemania...”.

Texto 08: "Eu vinia para casa da minia tia".

d) Uso do til $(\sim)$ em palavras com nasalidade

Bortoni-Ricardo (2004) afirma que a nasalidade das vogais é indicada graficamente pelas consoantes $\mathrm{M}$ ou $\mathrm{N}$, grafada depois da vogal, e pelo til $(\sim)$. No texto 01 ocorreu a presença de palavras como: "matãn" (matam), "estrupãn” (estupram), "roubãn” (roubam). 
e) Acréscimo de vogais

O processo de ditongação, que é o acréscimo de vogais em sílabas monotongas é muito comum na oralidade, bem como o de monotongação. No caso da ditongação foi possível constatar nos textos escritos dos alunos do $5^{\circ}$ ano, como apresentam os textos 04 e 05:

Texto 04: “... os bandido fais a violência...”.

Texto 04: “... assim teim uma meninas...".

Texto 05: “... o mundo se feiz...”.

f) Palavras grafadas como um único vocábulo formal

Bortoni-Ricardo (2005) afirma que nesses casos trata-se de vocábulos fonológicos constituídos de duas ou mais formas livres dependentes e grafados como um único vocábulo formal. Em alguns textos foram encontradas palavras como: "uque"(o que), "queda"( que da), "poraî"(por ai).

Com base nos dados acima é possível identificar a existência de marcas da oralidade na produção textual dos alunos. Constatamos a presença dos seguintes fenômenos: a) troca de vogais por outras e/ou por consoantes; b) supressão das consoantes " $r$ " e "s"; c) omissão dos dígrafos; d) uso do til ( ) em palavras com nasalidade; e) acréscimo de vogais; f) palavras grafadas como um único vocábulo formal.

Em suma, essa situação pode acontecer em decorrência do aluno ainda não conseguir diferenciar a língua oral da língua escrita ou por não dominar os critérios da língua escrita e tampouco saber que existem espaços onde o uso das respectivas línguas se adequam.

\section{CONSIDERAÇÕES FINAIS}

Os resultados desta pesquisa ratificam as ideias apresentadas por Bortoni-Ricardo (2005), uma vez que se detectou que os alunos do $5^{\circ}$ ano da escola pesquisada não percebem a diferença do texto oral para o texto escrito, pois eles ainda estão em processo de aquisição de textos formais.

A forte presença de elementos linguísticos da fala nos textos escritos é comum nos anos inicias. Nesta fase o aluno se encontra em período de aquisição e desenvolvimento do uso da escrita. Com isso, percebemos que o professor no uso de suas funções enquanto mediador do conhecimento precisa intervir mostrando que o aluno deve adequar suas variedades linguísticas às normas de prestígio da língua portuguesa.

Observamos também que no decorrer da pesquisa a criança tem uma tendência a escrever da maneira como fala e dar-se por satisfeita por atender suas necessidades comunicativas, por isso, a intervenção do professor é de fundamental importância para viabilizar o ajuste da escrita, sem menosprezar as diferenças relacionadas ao repertório dos falantes. Para tratar desses eventos, sugerimos que o professor trabalhe com a refacção e a reescrita textual das produções dos alunos, estimulando-os a refletir sobre o que escrevem, como escrevem e para quem escrevem.

\section{REFERÊNCIAS}

ANTUNES, I. Aula de Português: encontro e interação. São Paulo: Parábola, 2003.

ANTUNES, I. Gramática contextualizada: limpando "o pó das ideias simples". São Paulo: Parábola, 2014.

BAGNO, M. Português on Brasileiro? Um convite à pesquisa. 4. ed. São Paulo: Parábola, 2004.

BORTONI-RICARDO, S. M. Educação em Lingua Materna: a sociolinguística em sala de aula. São Paulo: Parábola, 2004.

BORTONI-RICARDO, S. M. Nós chegemu na escola, e agora? Sociolinguística e educação. São Paulo: Parábola, 2005.

BORTONI-RICARDO, S. M. O professor pesquisador: introdução à pesquisa qualitativa. São Paulo, 
2008

CAGLIARI, L. C. Alfabetização e linguística. 6. ed. São Paulo: Scipione, 1993.

MARCUSCHI, L. A. Fala e escrita. Belo Horizonte: Autêntica, 2007.

MARCUSCHI, L. A. Gêneros Textuais: definição e funcionalidade. In: DIONISIO, A; MACHADO, A.; BEZERRA, M. (Orgs.). Gêneros textuais e ensino. Rio de Janeiro: Lucena, 2004. p. 19-38.

Enviado em: 26/01/2020

Aceito em: 20/06/2020

\section{https://periodicos.unifap.br/index.php/letras}

Macapá, v. 9, n. 4, $2^{\circ}$ sem., 2019 